\title{
Effect of glass addition on the properties of cements (CEMI)
}

\author{
Morsli $\mathrm{H}^{1,}{ }^{*}$, Chaid R${ }^{1}$, Molez L², Diouri A ${ }^{3}$ \\ 1 UMB, Boumerdes, Algeria \\ 2 INSA, Rennes, France \\ 3 Faculty of Science, Rabat, Morocco \\ * Corresponding author's e-mail: hamza_morsli@yahoo.fr
}

Received: 09-02-2018

Revised: 12-04-2018

Accepted: 18-04-2018

\begin{abstract}
The purpose of this study is to recover mineral residues as an additive in cementbased building materials. It is part of a sustainable development approach. The use of recovered and recyclable industrial residues in partial replacement of Portland cement reduces greenhouse gas (GHG) emissions and results in the manufacture of cement with a lower environmental impact.

Using various experimental techniques, particular attention is paid to the behaviour of the glass powder finely crushed and chemically activated associated with Portland cement. This study confirms the improvement in the physicochemical and mechanical properties of cements with the addition of glass powder, which augurs well for its use as a cement additive.
\end{abstract}

Key words: Cement, Glass, Addition, Activation.

\section{Introduction}

Different mineral additions are currently used in cement. They are used as substitution to cement. The use of these supplementary cementitious materials provides to mortar a denser matrix that will be more resistant to aggressive environments such as sulphates, chlorides and other aggressive agents.

The fineness of mineral additions, their chemical composition, their structure (glassy or crystalline), their pozzolanic activity and their solubility in alkaline medium govern their cementing properties in mortar. Their content in amorphous phase is a key factor in the reactivity of the mineral additions (Tagnit and Nkinamubanzib, 2001).

Glass is obtained primarily from the fusion of silica sand (>99\% silica) and hence could be a pozzolanic material. As the use of glass increases steadily, glass waste increases accordingly. There are many alternatives for glass reuse. According to some studies (Kojima et al., 2000), most methods of reuse require preliminary preparation such as milling and hence could not be well developed and are unable to absorb the large quantities of waste glass. An alternative sustainable solution could be the reuse of waste glass in concrete (Roz-Ud-Din and Parviz, 2012). Indeed, for economic and environmental reasons, the use of recycled glass in cement and concrete has attracted the interest of many municipalities which encouraged further studies (ACI 116R-90, 2000).

The development of using waste glass as coarse or fine aggregates or as cement replacement material was hindered because of the risk of alkali-silica reaction (ASR) and other durability properties. However, De Castro and de Brito (2013) analyzed the effect of using fine and coarse glass aggregates on the durability performance of concrete and concluded that concrete with glass aggregates is completely feasible and that in most cases the glass aggregates do not alter the durability-related properties of concrete such as water absorption by capillarity and immersion, carbonation and chloride diffusion. Oliveira et al. (2013) analyzed the effect of very fine glass aggregates in rendering and found that mechanical strength and durability properties are improved with the incorporation of up to $20 \%$ of fine glass aggregate. The incorporation of 
fine glass waste aggregates improves the mechanical performance of mortar especially for replacement ratios around 20\% (Penacho et al., 2014).

Corinaldesi et al. (2004) found no detrimental effect of the glass particles (smaller than $100 \mathrm{~mm}$ ) when they replaced 30 and $70 \%$ of the mass of sand with glass aggregates. Shayan and $\mathrm{Xu}$ (2006) and Taha and Nounu (2008) also concluded that there was no expansive reaction related to the incorporation of glass and powder to replace natural sand and cement, respectively. The glass powder led to changes in the concentration of hydroxide ions $\left(\mathrm{OH}^{-}\right)$in the matrix pores. This is considered to be the direct cause of the reduced risk of expansion due to ASR. Since the pozzolanic reaction occurs earlier than ASR, the alkaline content of the paste is consumed in the creation of hydrated $\mathrm{C}-\mathrm{H}-\mathrm{S}$ gels, and there are not enough ions in the later stages of cement hydration.

Serpa et al. (2013) concluded that the incorporation of glass as cement replacement or even as aggregate can decrease the ASR effects. Its efficiency is related with the replacement ratio and size. Glass can be used in substitution of natural, non-alkali reactive aggregates up to $20 \%$ ratio, particularly if limestone natural aggregates are involved. Du and Tan (2013) found that the ASR expansion also decreased with smaller glass particle size due to pozzolanic reaction of fine glass particles. Idir et al. (2010) observed that the finer the glass powder, the better it will perform in counteracting the ASR expansion effects.

This paper reports on a part of an ongoing research project on the reuse of mineral waste materials as an addition to cement for the development of sustainable cement.

We discuss on $\mathrm{NaOH}$ effect on physic-mechanical properties of cement mainly the results of an experimental study on the effect of finely crushed glass.

\section{Materials used}

\subsection{Cement}

The cement used was a local Portland cement type CEM I 42.5N/SR5 without addition. The chemical and mineralogical compositions of the cement are summarized in Table 1 and Table 2 summarizes physical and mechanical characteristics of the cement.

\subsection{Standard sands}

The sand, of which a limited stockpile is maintained as reference material, is natural, siliceous sand consisting of rounded particles and has a silica content of at least $98 \%$.

CEN Standard sand shall comply with the particle size distribution specified in Table 3 as determined by sieve analysis on a representative sample of sand of total mass not less than 1345g. Sieving shall be continued until the amount of sand passing through each sieve is less than $0,5 \mathrm{~g} / \mathrm{min}$. The moisture content shall be less than $0.2 \%$ determined as the loss of mass of a representative sample of sand after drying at $105^{\circ} \mathrm{C}$ to $110{ }^{\circ} \mathrm{C}$ to constant mass and expressed as a percentage by mass of the dried sample.

Other characteristics like Sand equivalent, Methylene blue test and finesse module are presented in Table 3.

Table 1. Chemical and mineral compositions of the cement.

\begin{tabular}{|c|c|c|c|c|c|c|c|c|c|c|c|c|}
\hline Elements & $\mathrm{SiO}_{2}$ & $\mathrm{Al}_{2} \mathrm{O}_{3}$ & $\mathrm{Fe}_{2} \mathrm{O}_{3}$ & $\mathrm{CaO}$ & $\mathrm{MgO}$ & $\mathrm{SO}_{3}$ & $\mathrm{~K}_{2} \mathrm{O}$ & $\mathrm{Na}_{2} \mathrm{O}$ & $\mathrm{IR}$ & $\begin{array}{c}\text { Free } \\
\mathrm{CaO}\end{array}$ & LOI & $\mathrm{Cl}^{-}$ \\
\hline \hline$\%$ & 20.93 & 4.81 & 5.19 & 64.22 & 1.31 & 2.08 & 0.30 & $<0.05$ & 0.74 & 0.474 & 0.740 & $<0.01$ \\
\hline Minerals & \multicolumn{2}{c}{$\mathrm{C}_{3} \mathrm{~S}$} & \multicolumn{2}{c}{$\mathrm{C}_{2} \mathrm{~S}$} & \multicolumn{2}{c|}{$\mathrm{C}_{3} \mathrm{~A}$} & \multicolumn{2}{c}{$\mathrm{C}_{4} \mathrm{AF}$} & Free $\mathrm{CaO}$ & Gypsum \\
\hline$\%$ & 60 & \multicolumn{2}{c}{15} & \multicolumn{2}{c|}{04} & \multicolumn{2}{c|}{16} & \multicolumn{2}{c|}{$<0.01$} & 05 \\
\hline
\end{tabular}


Table 2. Physical and mechanical characteristics of the cement.

\begin{tabular}{|c|c|c|c|c|}
\hline \multicolumn{2}{|c|}{ Physical characteristics } & \multicolumn{3}{c|}{ Mechanical characteristics } \\
\hline \hline Initial setting time (mn) & 190 & Age (days) & Flexure(MPa) & Compressive (MPa) \\
\hline Final setting time (mn) & 295 & 2 & 4.4 & 16.7 \\
\hline Density (g/cm $\left.{ }^{3}\right)$ & 3.2 & 7 & 6.4 & 34.4 \\
\hline $\begin{array}{c}\text { Specific surface (SSB) } \\
\left(\mathrm{cm}^{2} / \mathrm{g}\right)\end{array}$ & 2900 & 28 & 6.6 & 55.3 \\
\hline
\end{tabular}

Table 3. Particle size distribution of the CEN Reference sand.

\begin{tabular}{|c|c|c|c|c|c|c|}
\hline Square mesh size (mm) & 2.00 & 1.60 & 1.00 & 0.50 & 0.16 & 0.08 \\
\hline \hline Cumulative sieve residues (\%) & 0 & $7 \pm 5$ & $33 \pm 5$ & $67 \pm 5$ & $87 \pm 5$ & $99 \pm 1$ \\
\hline Sand equivalent (\%) & \multicolumn{6}{|c|}{0.0} \\
\hline 90 & \multicolumn{6}{|c|}{0 finesse module } \\
\hline
\end{tabular}

\subsection{Glass powder}

The glass powder is obtained through grinding waste glass. The fineness of the glass was assured by Air Permeability Method (Blaine Method). The physical and chemical characteristics of the powder are given in Tables 4 and 5 . The absence of peaks in the diffraction diagram of the glass powder (Fig. 1) confirms its amorphous state and hence its pozzolanic activity.

Table 4. Chemical composition of the glass powder.

\begin{tabular}{|c|c|c|c|c|c|c|c|c|c|c|c|}
\hline Elements & $\mathrm{SiO}_{2}$ & $\mathrm{Al}_{2} \mathrm{O}_{3}$ & $\mathrm{Fe}_{2} \mathrm{O}_{3}$ & $\mathrm{CaO}$ & $\mathrm{MgO}$ & $\mathrm{SO}_{3}$ & $\mathrm{~K}_{2} \mathrm{O}$ & $\mathrm{Na}_{2} \mathrm{O}$ & $\mathrm{P}_{2} \mathrm{O}_{5}$ & $\mathrm{TiO}_{2}$ & LOI \\
\hline \hline$\%$ & 73.06 & 0.90 & 0.74 & 9.26 & 1.78 & 0.33 & 0.32 & 12.29 & 0.00 & 0.03 & 1.29 \\
\hline
\end{tabular}

Table 5. Physical characteristics of the glass powder.

\begin{tabular}{|c|c|}
\hline Density & $2.55\left(\mathrm{~g} / \mathrm{cm}^{3}\right)$ \\
\hline \hline Specific surface & $8300\left(\mathrm{~cm}^{2} / \mathrm{g}\right)$ \\
\hline Colour & White grey \\
\hline
\end{tabular}

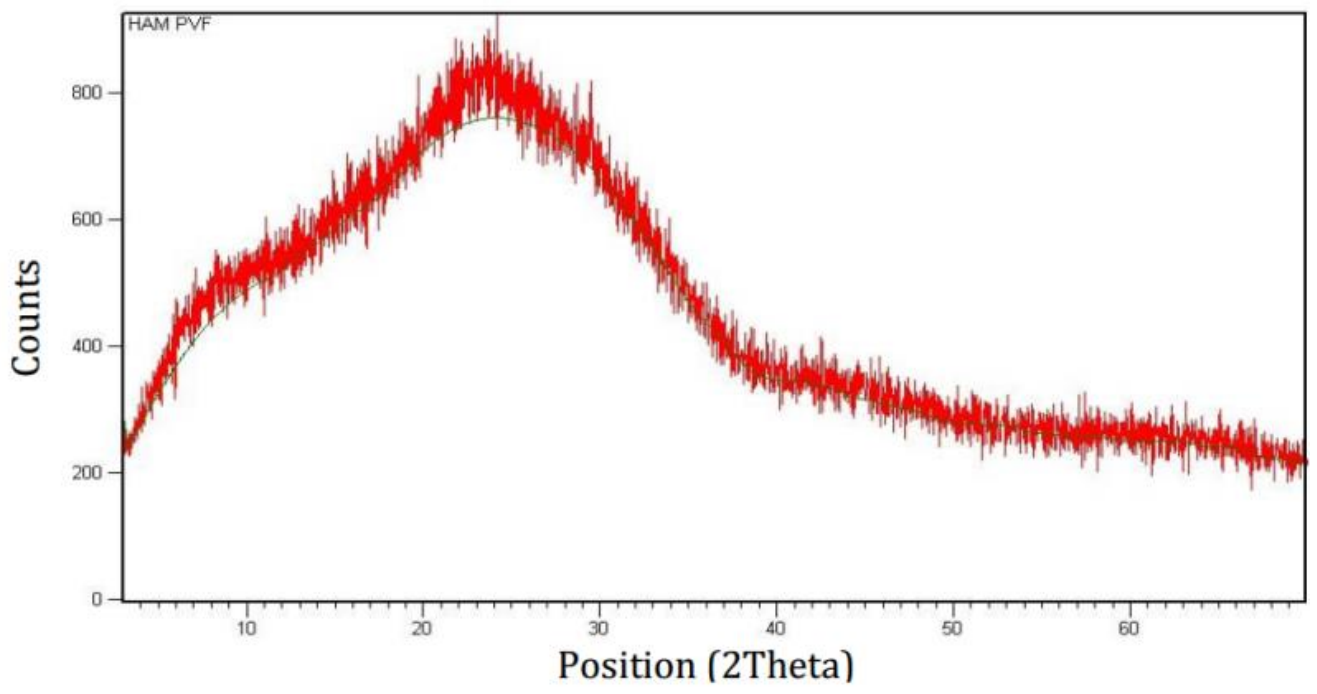

Fig 1. X-ray diffraction of the glass powder.

The simplest way to describe the pozzolanicity of a material is to evaluate the decrease of free lime in the system and also the kinetics of the reaction. Generally, the parameters influencing the nature of the pozzolanic reactions are the nature of active phases and their proportions (Lea, 2004). Fig. 2(a) illustrates the volume of $\mathrm{HCl}$ necessary for the neutralisation of the solution of lime in the presence of glass powder over time. The stabilization is noted from the $18^{\text {th }}$ day. Fig. 2 (b) shows the pozzolanic reactivity of glass compared with that of silica fume and fly ash. The 
ratio of the combined lime by glass powder is identical to that of the fly ash. However, silica fume is the most reactive cementitious addition (Chaïd et al., 2015).
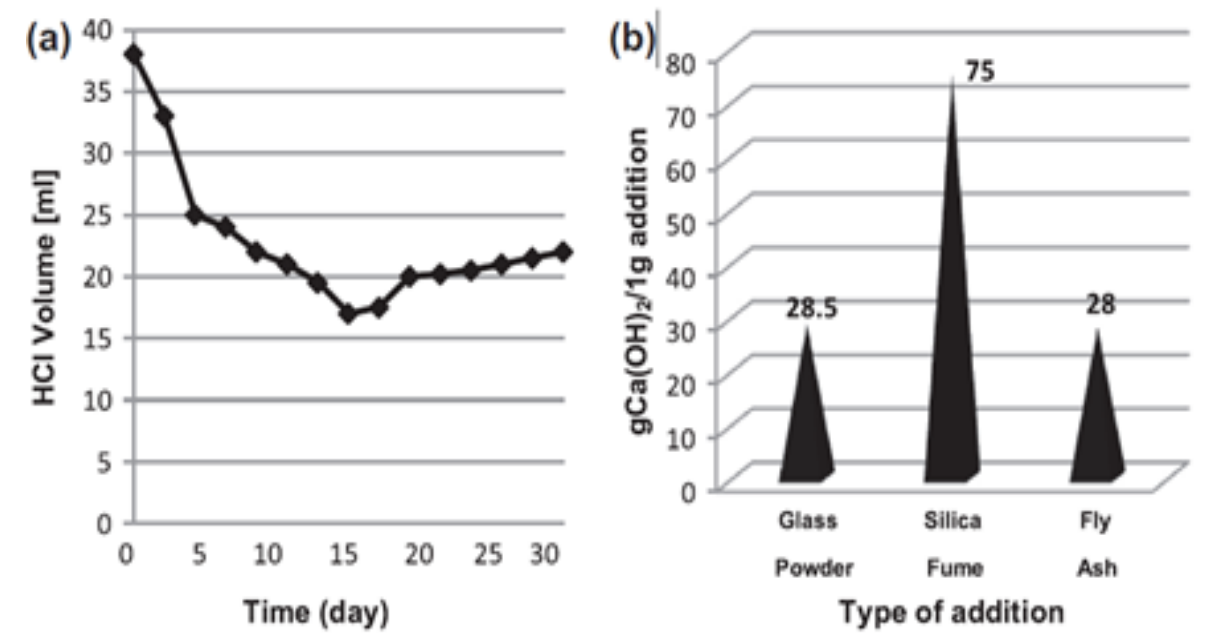

Fig 2. (a) Volume of consumed HCl; (b) Pozzolanic activity of the glass powder.

\subsection{Sodium hydroxide}

Derives from sodium carbonate; formerly named caustic soda. In Ancient Egypt, sodium carbonate was already mixed with lime to synthesize an alkali: the hydroxide ion $\mathrm{OH}$ - in solution with the sodium ion $\mathrm{Na}^{+}$. Through the ages, several processes were developed to synthesize it, such as the Solvay process in 1861. Today, sodium hydroxide is mostly produced by the electrolysis of a solution of sodium chloride.

In this study we used sodium hydroxide in pellets (Fig 3), before adding it to the cement mixture the soda is prepared by grinding it with a porcelain mortar, Table 6 represents physical and chemical characteristics of sodium hydroxide.

Table 6. Physical and chemical characteristics of sodium hydroxide.

\begin{tabular}{|c|c|}
\hline Formula & $\mathrm{NaOH}$ \\
\hline Molar mass & 40 g.mol$^{-1}$ \\
\hline Colour & White \\
\hline State & solid \\
\hline
\end{tabular}

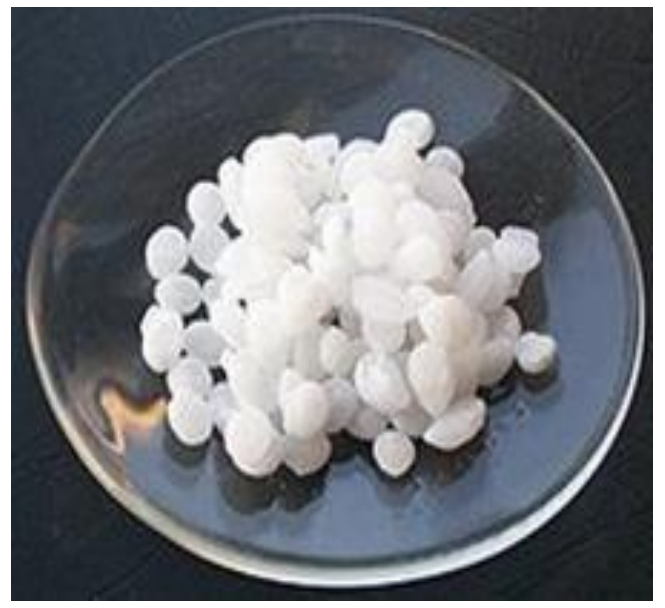

Fig 3. Sodium hydroxide in pellets. 


\section{Experimental procedure}

\subsection{Substitution and characterization of cement paste}

Three mixtures with different proportions of glass powder $10 \%, 20 \%, 30 \%$ and one without addition to determine the standard consistence, initial and final setting time. We obtained the results presented in the figures 4 and 5 . These tests shall be carried out in accordance with the terms of EN 196-3.

\subsection{Preparation and characterization of mortars}

The same combination of cement is used with standardized sand and water for the preparation of mortar which is used to calculate mechanical strength at different age 2,7 , and 28 days and this serves to retain the best variant of substitution to activate it by sodium hydroxide, we obtained the results presented in the figures 6 and 7. These tests shall be carried out in accordance with the terms of EN 196-1.

\subsection{Alkaline activation}

After selecting the best variant, the initial and final setting time are determined while adding $(0.5,1,1.5$ and $2 \%)$ of the sodium hydroxide calculated with respect to the level of the glass powder added to the cement mixture, at the end the variant which has the lowest initial setting is selected to determine the mechanical strength with the addition of a better percentage of sodium hydroxide add as solution form and as powder form to the mortar according to the terms of EN 196-1.

\section{Results and discussion}

\subsection{Standard consistence, initial and final setting}

According to Fig. 4 that the addition of the finely grinding glass powder by substitution of cement increases the consistency value in a manner proportional to the percentage of the glass powder. The addition of $30 \%$ of glass powder by substitution of cement requires $2.5 \%$ water to have the same consistency as that without addition.

The addition of $\mathrm{NaOH}$ to the $10 \%$ glass powder variant reduces the consistency if the dosage is less than $1.5 \% \mathrm{NaOH}$ but in otherwise the water requirement increases for the same consistency.

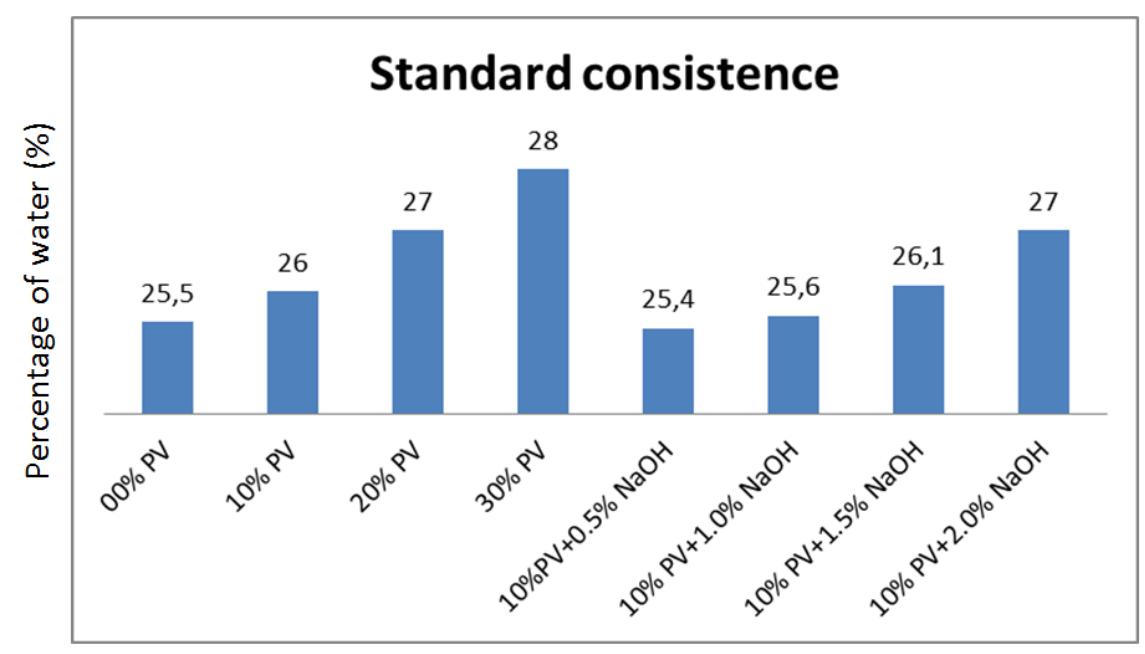

Fig 4. Standard consistence of the different variants. 


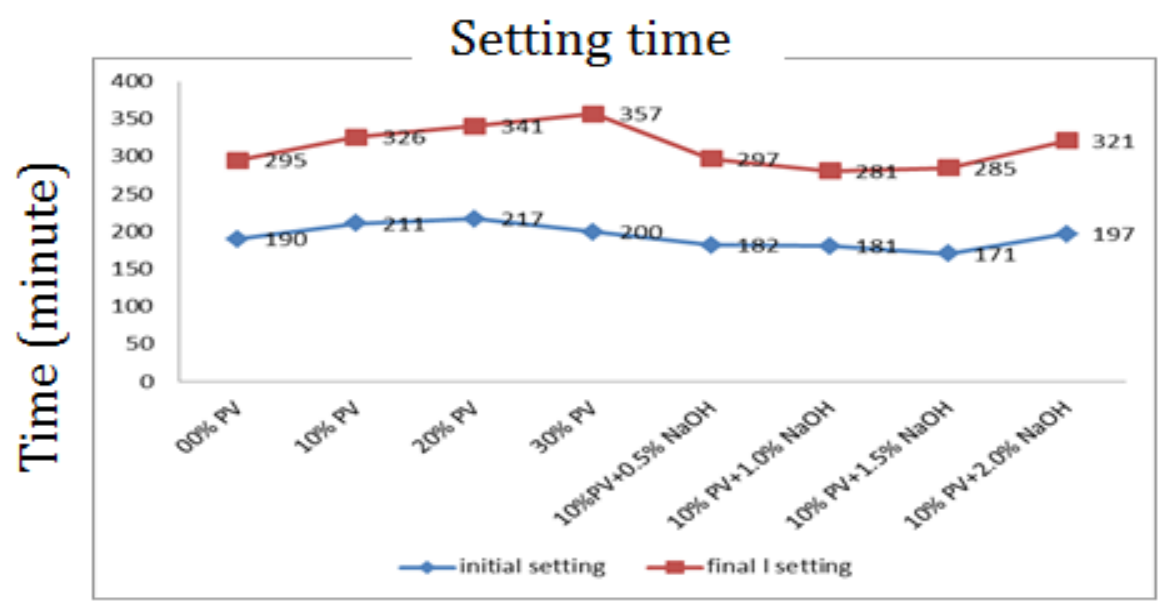

Fig.5. initial and final setting of the different variants.

By adding $10 \%$ of glass powder by substitution of cement gave a 21 minute delayed initial setting with respect to that without addition, but that which had $30 \%$ of glass powder had an initial setting lower than those of $10 \%$ and $20 \%$, this is due to the presence of $\mathrm{Na}_{2} \mathrm{O}$ in the glass composition which is of the order of $12 \%$ (Table 4), which is confirmed by the addition of $\mathrm{NaOH}$ to the $10 \%$ variant (Fig. 5).

From Figure 5 it can be said that the addition of $1.5 \% \mathrm{NaOH}$ gave the lowest initial setting which is an indication of an acceleration of the hydration kinetics.

It is this embodiment which has been chosen for the determination of the mechanical strength by adding sodium hydroxide solution and powder in a mortar; these results are shown in the following figures.

\subsection{Mechanical strength without activation}

Figures 6 and 7 are a column presentation of the values of the mechanical strength of compression and of flexion respectively at the different ages 2, 7 and 28 days for each variants it can be concluded that the addition of the glass powder by substitution of cement reduces the mechanical strength, but that the $10 \%$ glass powder variant gave a cement of $42.5 \mathrm{MPa}$ class is a same as without glass adding and that of $20 \%$ is classed as cement of $32.5 \mathrm{MPa}$.

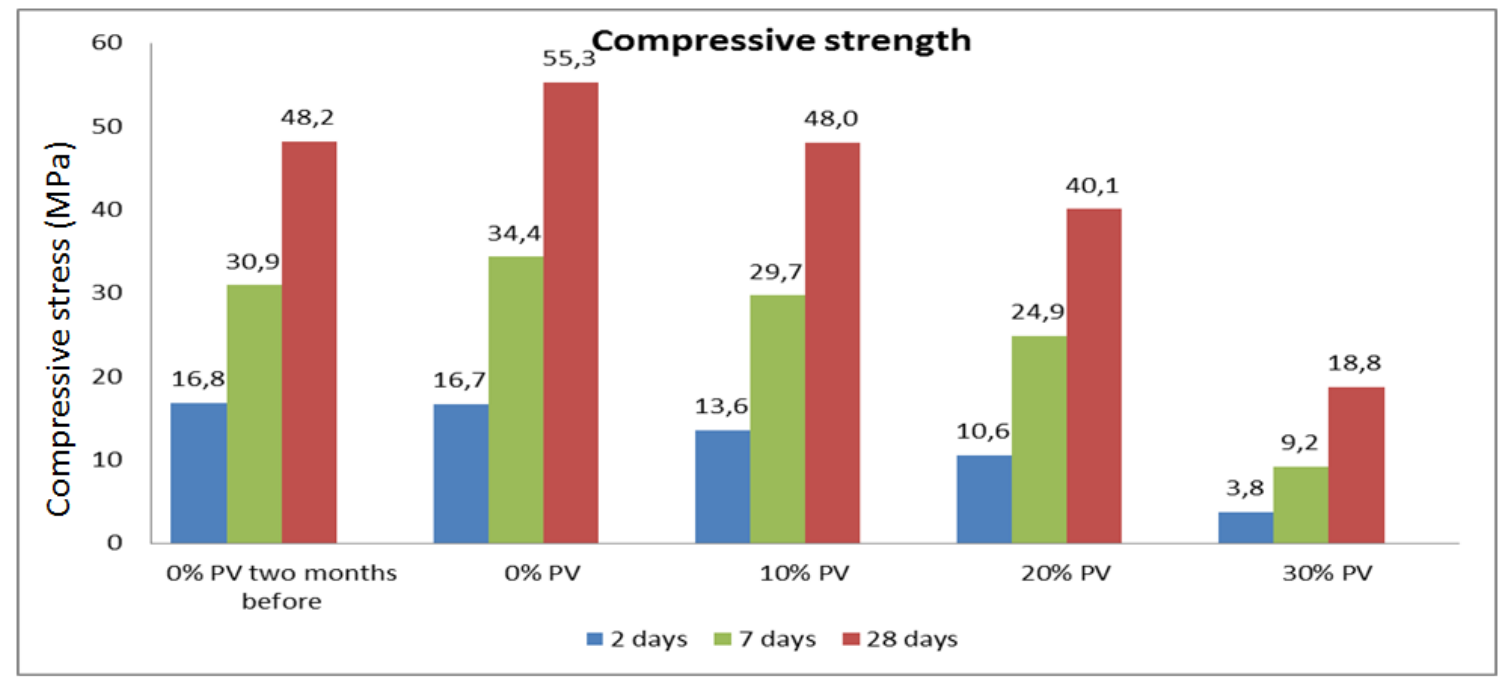

Fig 6. Compressive strength of the different variants. 
The value of the compressive strength of mortar without glass powder is $55.3 \mathrm{MPa}$, but this value was $48.2 \mathrm{MPa}$ two months before for the same cement bag, which is an indicator that the cement becomes more efficient if it is kept for a period before use away from moisture which is a cement hardener by hydration.

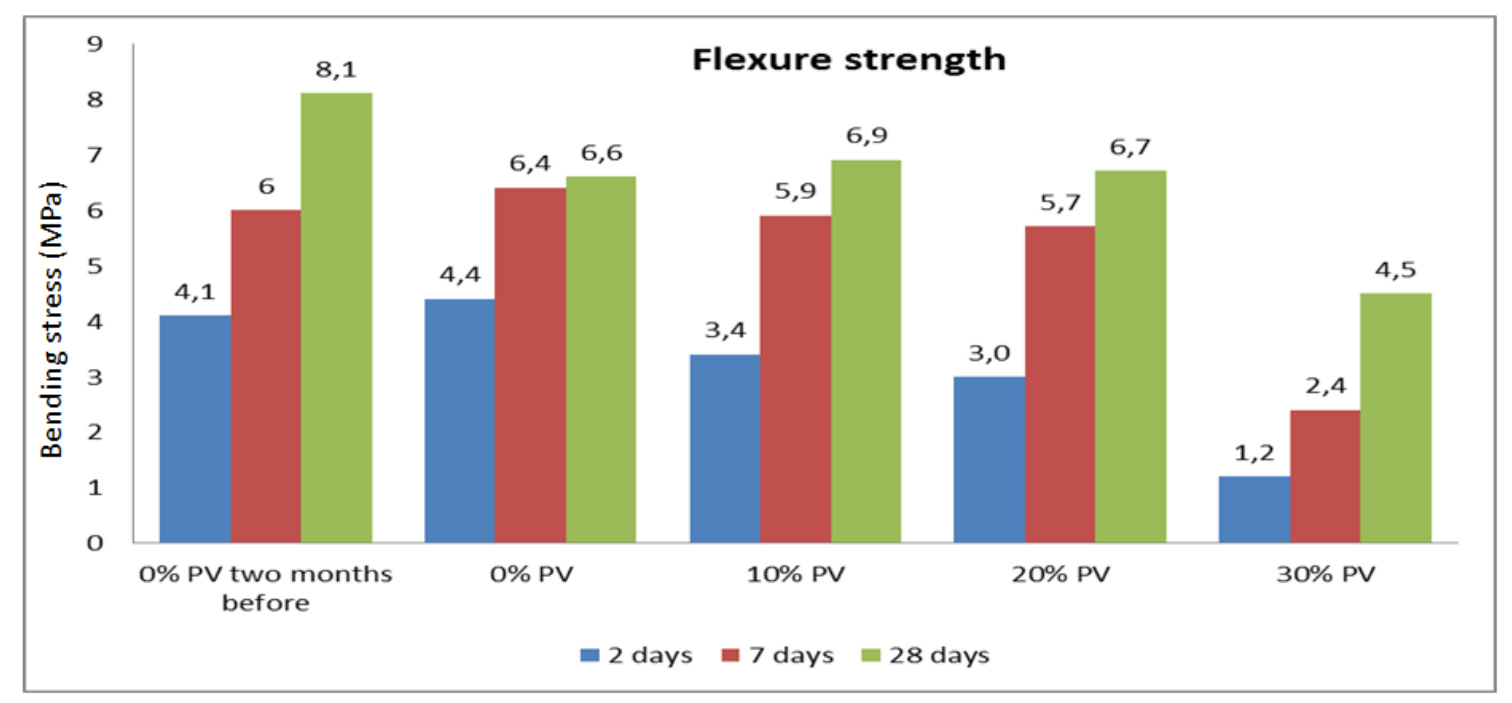

Fig 7. Flexure strength of the different variants.

The $10 \%$ variant of glass powder gave a value of $7 \mathrm{MPa}$ less compared to the mortar poured the same day without addition, but an equal value than the mortar poured two months before.

\subsection{Mechanical strength with activation}

Figures 8 and 9 are a column presentation of the values of the mechanical strength of compression and of flexion respectively at the different ages 2, 7 and 28 days.

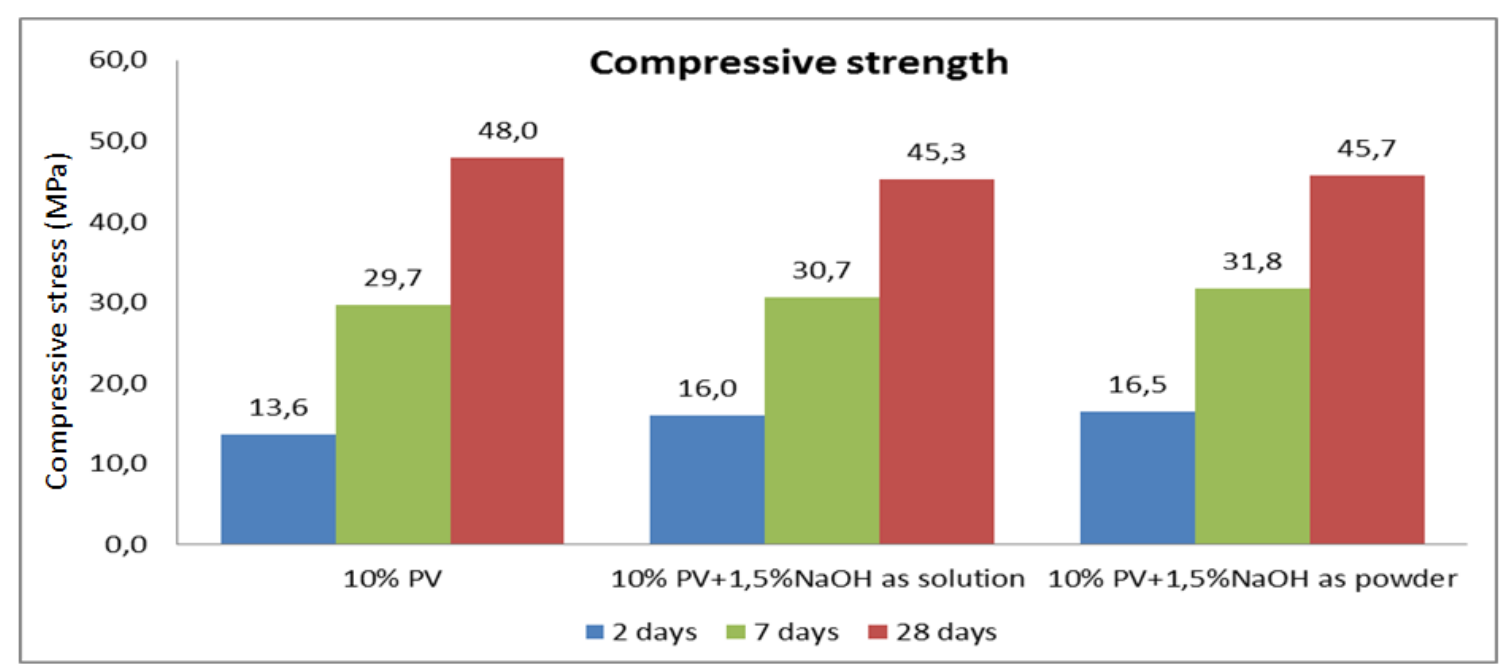

Fig 8. Compressive strength adding Sodium hydroxide as solution and as powder.

The results of compression and flexion by the addition of $\mathrm{NaOH}$ as solution and as powder in the $10 \%$ glass powder variant at the different age shows that addition of $\mathrm{NaOH}$ as solution to the mixture is easier than powder form because the $\mathrm{NaOH}$ powder absorbs the moisture from the air and becomes liquid, so if $\mathrm{NaOH}$ is used in cement it is preferable to add it with the mixing water according to the appropriate concentration. 


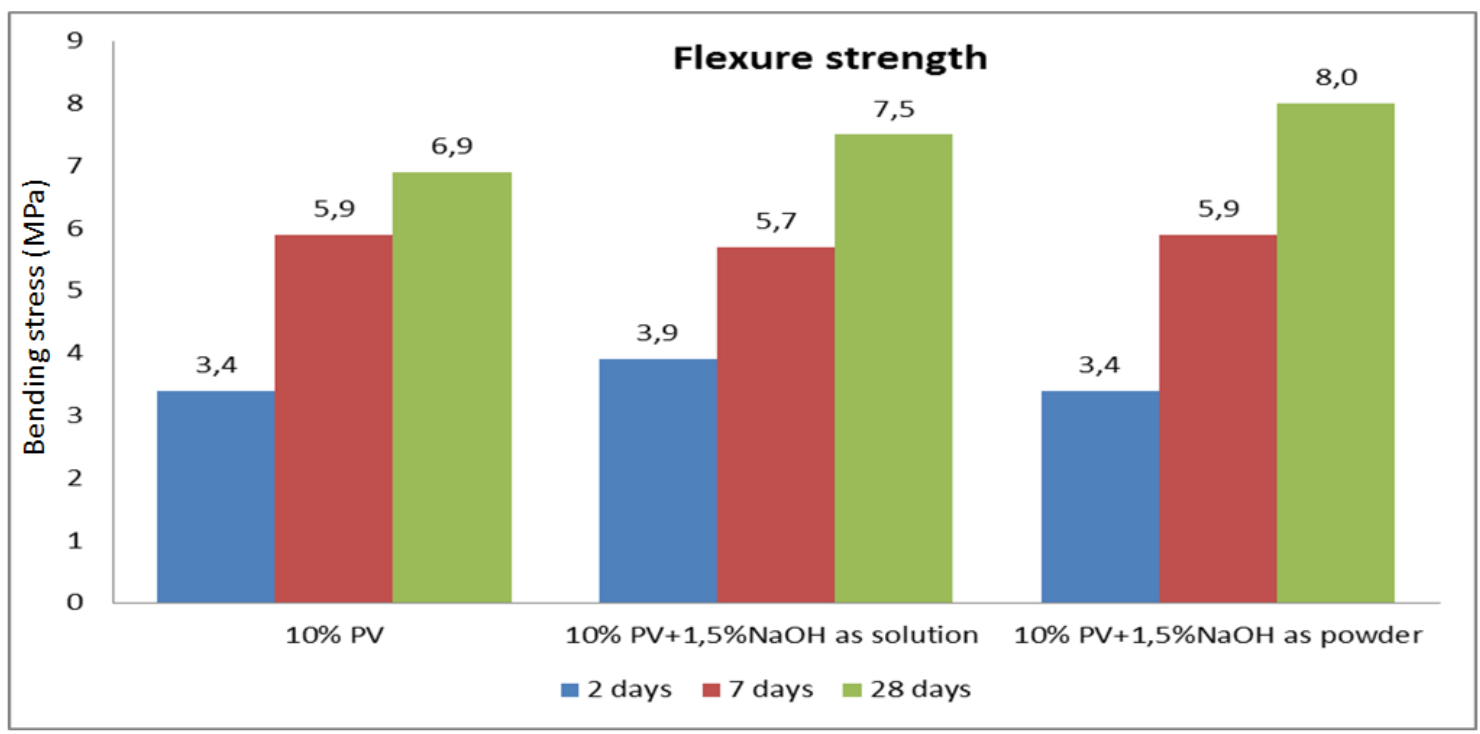

Fig 9. Flexure strength adding Sodium hydroxide as solution and as powder.

We notice that there was an improvement in mechanical strength at 2 and 7 days compared with that without activator, which was not the case in compression at 28 days which was a slight decrease of $2.5 \mathrm{MPa}$, Flexure strength has improved by $1 \mathrm{MPa}$ with respect to a without addition of $\mathrm{NaOH}$.

\section{Conclusion}

This study focused on the effect of the addition of finely ground glass powder on the physical and mechanical properties of a cement (CEM I) chemically activated by sodium hydroxide. It is noted that the addition of $\mathrm{NaOH}$ accelerates the setting of the cement, this induces the improvement of the mechanical strengths at the first ages ( 2 and 7) days.

These same resistances are reduced to 28 days, by about $5 \%$ with respect to the $10 \%$ variant of glass powder without activator. This leads us to say that sodium hydroxide has the same behaviour of an accelerating setting and curing accelerator.

An improvement in bending strengths at different ages is recorded, ranging from $14.5 \%$ to 28 days for cement with $10 \%$ added activated glass powder compared to that without activation, which is favorable for the structural elements subjected to bending forces.

The addition of $10 \%$ of glass powder to two main roles, the first one is economical, concerning the recovery of waste and the increase of the cement production, the second is ecological by the limitation of the emissions of the gases coming from the cement industry.

In the end, the chemical activation of silica-rich cementitious additions is an area of current interest that attracts the intention of quite a few researchers.

\section{References}

ACI 116R-90. (2000). Cement and concrete terminology, technical documents, American Concrete Institute.

Chaïd, R., Kenaï, S., Zeroub, H., \& Jauberthie, R. (2015). Microstructure and permeability of concrete with glass powder addition conserved in the sulphatic environment. European Journal of Environmental and Civil Engineering, 19(2), 219-237.

Corinaldesi, V., Gnappi, G., Moriconi, G., \& Montenero, A. (2005). Reuse of ground waste glass as aggregate for mortars. Waste Management, 25(2), 197-201. 
De Castro, S., \& de Brito, J. (2013). Evaluation of the durability of concrete made with crushed glass aggregates. Journal of Cleaner Production, 41, 7-14.

Du, H., \& Tan, K. H. (2013). Use of waste glass as sand in mortar: Part II-Alkali-silica reaction and mitigation methods. Cement and Concrete Composites, 35(1), 118-126.

Idir, R., Cyr, M., \& Tagnit-Hamou, A. (2010). Use of fine glass as ASR inhibitor in glass aggregate mortars. Construction and Building Materials, 24(7), 1309-1312.

Kojima, T., Takagi, N., \& Haruta, K. (2000). Expanding characteristics of mortar in glass powder produced from waste bottles, 673-682. 11 $1^{\text {th }}$ International Conference on Alkali Aggregate Reaction. Quebec, Canada, June 2000, 673-1282.

Oliveira, R., De Brito, J., \& Veiga, R. (2013). Incorporation of fine glass aggregates in renderings. Construction and Building Materials, 44, 329-341.

Penacho, P., de Brito, J., \& Veiga, M. R. (2014). Physico-mechanical and performance characterization of mortars incorporating fine glass waste aggregate. Cement and Concrete Composites, 50, 47-59.

Roz-Ud-Din, N., \& Parviz, S. (2012). Strength and durability of recycled aggregate concrete containing milled glass as partial replacement for cement. Construction and Building Materials, 29, 368-377.

Serpa, D., Silva, A. S., De Brito, J., Pontes, J., \& Soares, D. (2013). ASR of mortars containing glass. Construction and Building Materials, 47, 489-495.

Shayan, A., \& Xu, A. (2006). Performance of glass powder as a pozzolanic material in concrete: A field trial on concrete slabs. Cement and concrete research, 36(3), 457-468.

Tagnit, A., \& Nkinamubanzib, P.C. (2001). Les ajouts cimentaires et le développement durable, journée d'étude technique, Note trimestrielle d'information du Centre d'Etudes et de Services Technologiques de l'Industrie des Matériaux de Construction, CETIM, Algérie.

Taha, B., \& Nounu, G. (2008). Using lithium nitrate and pozzolanic glass powder in concrete as ASR suppressors. Cement and Concrete Composites, 30(6), 497-505. 